\title{
EFFECTS ABILITIES MOTION IN SPACE OF CHILDREN WHO ARE DEAF OR HARD-OF-HEARING, WITHOUT USE OF EYESIGHT
}

Husnija Hasanbegović ${ }^{1}$

Faculty of Education and Rehabilitation, University of Tuzla

\author{
Original scientific paper
}

UDC: $159.943 .8-056.263$

612.766-056.263
Received: 08.06.2014.
Accepted: 11.08.2014.

\begin{abstract}
This study investigates knowledge on use of body extremities and body in space by children who are deaf or hard-ofhearing. A random sample of 60 participants was used in the study, with chronological age of 6 to 8 years. Experimental group of 30 participants involved pupils who are deaf or hard-of-hearing both male and female who attend school in Sarajevo (Bosnia and Herzegovina). Control group of 30 participants involved pupils who are typically hearing both male and female who were chronologically matched to the participants in the experimental group. Measuring instruments were created for the purpose of extracting quantitative data analysis, scaled from 1 to 5 units of measurement. The results are showed significant differences between children who are deaf or hard-of-hearing and children who are typically hearing $(F=23,08 p=0.00)$. The children who are deaf or hard-of-hearing showed significantly weaker knowledge of perception of body movements.
\end{abstract}

Key words: Perception of body movements, recognition of dotted shapes, forward and backward walking.

\section{INTRODUCTION}

We learn most of our basic motor skills during infancy and childhood and acquire different and more refined motor skills throughout adult life. Highly coordinated movements develop gradually from simpler components. Most motor skills require good body balance, which develops gradually during the first year of life. Parents recognize the importance of balance when they applaud their babies' first steps. Spatial orientation is connected to awareness, body, movement and time. As a child becomes more familiar with his own body, it moves various body parts and brings objects into its personal space. As a child starts to walk, he familiarizes himself with the surrounding space and all things within that space. Whenever we move the three basic functions of movement, balance, and coordination work in concert to produce purposeful motions of body parts. Coordination is the essence of motor skill. For coordination, movements of the body, head, and eyes are important to maintain gaze in the direction of forward motion (Imai, Moore, Raphan, Cohen, 2001). Walking is produced by contracting all the muscles of the legs at different intensities and at different times. This is the essence of coordination, which applies equally well to muscles, joints, and whole body parts. Superimposed on coordinated movements is our sense of body balance, which helps us maintain our posture in response to gravity.

The infant's earliest responses to auditory stimuli include the visual-motor behaviour of moving the eyes or head to localize sound (Gheysen et al, 2008). Motion is a universal manifestation of a human's life, the basic form of his activity and most widely used agent in contacts with the surrounding environment. It is also the main factor of human development and improvement (Raczek, et al., 1998, per Zwierzchowska, et, al., 2008).

\footnotetext{
${ }^{1}$ Correspodence to:

Husnija Hasanbegović, Faculty of Education and Rehabilitation, University of Tuzla

Branilaca Banovića 76, Banovići, BiH

Phone: +387 61739089

E-mail: husnijamaj@hotmail.com
} 
As a child masters the concept of space, he also masters the concept of time, due to the fact that in order to get from one object to another, it is necessary to understand time and possess a certain amount of knowledge.

It is not known with a certainty how a child who is deaf or hard-of-hearing perceives space and time. Auditory deprivation may engender changes within dorsal-visual pathways that affect spatial-visual attention in a highly specific fashion (Corina, Singleton, 2009). Marchark (2003) states that there is no improvement of visual perception or visual spatial perceptions with persons who are deaf or hard-ofhearing, but contrary to that, they might have more problems with sight in relation to persons who are typically hearing. He also states that the visual modality is important for persons who are deaf or hardof-hearing, and depending on specific type of spatial assignment they use, deaf persons can accomplish better, worse or similar results in comparison to persons who are typically hearing. Hearing disorders play a complex role in development of personality. A child's psychosomatic development is conditioned by its activity, which is particularly expressed in the first years of development within the areas of mobility. Synchronization of movements with sounds is not equally or similarly expressed in children who are typically hearing and those with a hearing loss, which may lead to a significant difference in mastering the development of coordinated movements. Most common characteristics of mobility development of deaf persons include disorders or difficulties in maintaining static and especially dynamic balance, as well as a lack of steadiness in the areas of performing rhythmic movements and general macro and micro movements.

Differences between children who are deaf or hardof-hearing and children who are typically hearing can be observed in early periods of life. Because a child who is deaf or hard-of-hearing does not hear the sounds of a mother's laughter, cries and tender cooing, or one's own crying, it leads to the impediment of the overall development of physical or psychological awareness and experience. To a child who is deaf or hard-of-hearing, movements give a sense of social interaction during the exchange, which in turn allows the awareness of motor mobility to provide for natural space awareness.

The move enables child who is deaf a social relation within the communication, while the movement experience gives the natural sense about space on which basis is the image and belief created later. The cognition implies the process of receive and processing of information which are used to human orientation between objects and appearances in the world which is the adaptive function of cognition. The surveys that are related to organization of space knowledge at children who are deaf can give the guidance education and rehabilitative models. Also the development of space orientation depends on stimulation of environment. The children who are deaf should be permanently encouraged for development of space orientation and the determining positions in space through guided activities. Every survey about achievements of children who are deaf in cognitive development point that children who are deaf significantly fall behind at all areas of education. So this survey shows that children who are deaf achieve worse results in memorizing and repeating the moves of body parts with eyes closed than children who are typically hearing. The child who is deaf or hard-ofhearing needs to be frequently stimulated through directed and specialized activities aimed at greater development of spatial orientation and determination of position in space. This study of children who are deaf or hard-of-hearing and their movements in space and manipulated fields is designed to address the following hypothesis: There are statistically important differences between children who are typically hearing and children who are hard of hearing or not hearing at memorizing the body movements at environment of low visibility or dark.

\section{METHOD}

The study includes a total sample of 60 randomly chosen participants between the ages of 6 and 8 . In order to examine the research hypothesis and goals of the study, the total sample is divided into two subsamples. The first sub-sample of participants $(\mathrm{N}=30)$ was the experimental group and included participants who are deaf or hard-of-hearing of primary school age, attending the Centre for Hearing and Speech Rehabilitation in Sarajevo. Fifty-six percent of participants were male and $43.3 \%$ were female within the experimental group. The second subsample of participants $(\mathrm{N}=30)$ was the control group and included participants who are typically hearing, were chronologically matched to the participants in the experimental group. In order to measure the ability to memorize leg movements and spatial perception with the help of one's own body, a classroom was set up painted footprints of different colours on the floor. 
The experimental group of deaf children were the first to participate. Without previous preparations, children were asked to walk forward, in a succession, making sure to step on the painted footprints on the floor. After all children concluded the activity, they were then blindfolded with a scarf and asked to repeat the exercise of walking on the footprints, trying their best to remember the position of the footmarks. The same instructions were given for the following activity of walking backwards on the painted footprints. The control group, which included children who are typically hearing of the same chronological age as the participants of the experimental group, completed the same exercise of walking forward and backwards, with eyes open as well as blindfolded. The results of the control group are then compared with those of the experimental group in order to test the hypothesis.

\section{MEASURING}

For measuring results of the research this study, a battery of tests was used, which were metrically standardized by quantitative method of evaluation, satisfying the criteria of reliability, validity, objectivity and sensitivity aaccording to statistical examinations at preliminary surveys. The measuring instrument is outlined and constructed in a way that it is fully adjusted to experimental conditions of quantitative data analysis, with measuring units scaled from 1 to 5 .

For research in this work, two tests were used. The test, "Traces" consisted of an experimental program in which the children were successively included in the experiment, in a way that within a space measuring a distance of 3 meters ( 5 steps); they walked forward and backwards on previously traced footsteps on the floor. This test consists of 2 sub-tests: walking forward and walking backward on marked traces of footsteps. The experiment consisted of two activities in which a child participates in an attempt to precisely walk on previously prepared traces of footsteps, first with eyes open, then with eyes closed or blindfolded. Evaluation of the results was done by monitoring the success of the participant for correctly stepping on the footsteps, resulting in a grade from 1 to 5. Each child participated in two attempts for each direction, forward and backwards. The goal of this test is to determine body perception in relation to a narrow space of body manipulation, which is the skill and capability represented in cognitive space perception of per- sonal body manifestations. Personal body manifests are related to memorizing of body moves which is characteristic to deaf population for communication by the body language or sign language. Generally it is known that children who are deaf develop their memory and cognition on the basis of body manifests, but the moves of legs and the body position are not examined enough especially at low visibility conditions.

\section{RESULTS}

For this research study, a description of basic statistical parameters is performed in order to conduct a research on cognitive space perception of children who are deaf or hard-of-hearing, such as examining movable elements of awareness functions within a manipulative field and space in which children who are deaf or hard-of-hearing operatively establish interactions with objective reality. In addition, tasks of examining movements and their influence on perception of marked shapes are prepared through activities of shape recognition by tactile sensory and visual discrimination. In order to investigate research hypothesis, a methodological data analysis was done through parametric evaluations, showing a comparative and descriptive analysis of basic statistical parameters between children who are deaf or hard-of-hearing and children who are typically hearing. Table 1 show results of the experimental program "Space perception of footsteps" where the children participated in the process of successively walking on the painted footsteps on the floor. Analysing the data, it can be concluded that the participants who are typically hearing, as a control group, showed better results than the children who are deaf or hard-of-hearing or an experimental group. Data shows that 16 participants or $55.3 \%$ of the controlled group correctly followed 5 footsteps, and 9 participants or $30.0 \%$ of the group correctly followed 4 footsteps while blindfolded. In the experimental group, deaf participants showed less overall success with the given task, where most participants $(30.0 \%)$ correctly followed only 2 steps and one participant was not able to successfully follow a single step while blindfolded. Based on the results obtained, it can be concluded that participants who are deaf or hard-of-hearing show unbalance in their sense of spatial organization after the visual sensors are masked (Table 1). 
Table 1. Space perception of lower extremities in the direction of forward walking

\begin{tabular}{lllll} 
Variables & \multicolumn{2}{l}{ Experimental group (Deaf) } & \multicolumn{2}{l}{ Control group (Hearing) } \\
\hline $\begin{array}{l}\text { Space perception of lower } \\
\text { extremities in the direction } \\
\text { of forward walking }\end{array}$ & $\mathrm{f}$ & $\%$ & $\mathrm{f}$ & $\%$ \\
\hline $\begin{array}{l}\text { 1 step } \\
\text { steps }\end{array}$ & 6 & 20.0 & 0 & 0 \\
3 steps & 9 & 30.0 & 1 & 3.3 \\
4 steps & 6 & 20.0 & 4 & 13.3 \\
5 steps & 3 & 10.0 & 9 & 30.0 \\
0 steps & 5 & 16.7 & 16 & 53.3 \\
\hline statistics & 1 & 3.3 & 0 & 0 \\
& & $\mathrm{M}=2.83$ & $\mathrm{M}=4.33$ \\
t-test for Equality & $\mathrm{S.D}=1.49$ & $\mathrm{df}=58$ & $\mathrm{p}=0.000$ \\
of Means & & $\mathrm{t}=-4.804$ & $\mathrm{df}=58$ & $\mathrm{p}=0.003$ \\
\hline $\begin{array}{l}\text { Levene's Test for Equality } \\
\text { Variances }\end{array}$ & of & $\mathrm{F}=9.874$ & & \\
\hline
\end{tabular}

Analysing data in Table 2, it can be concluded that the participants who are typically hearing of the controlled group, again, showed better results than the participants who are deaf or hard-of-hearing of the experimental group in the activity of backward walking on the painted footsteps on the floor. The frequencies show that 8 participants who are typically hearing or $26.7 \%$ of the controlled group correctly followed all 5 footsteps while walking backward, whereas only 2 deaf participants or $6.7 \%$ of the experimental group successfully followed 5 footsteps. Most participants who are deaf or hard-of-hearing (12 children or $40.0 \%$ of the group) were able to correctly follow 2 footsteps while walking backward (Table 2).

Table 2. Space perception of lower extremities in the direction of backward walking

\begin{tabular}{lllll} 
Variables & \multicolumn{2}{l}{ Experimental group (Deaf) } & \multicolumn{2}{l}{ Control group (Hearing) } \\
\hline $\begin{array}{l}\text { Space perception of lower } \\
\text { extremities in the direction } \\
\text { of backward walking }\end{array}$ & $\mathrm{f}$ & $\%$ & $\mathrm{f}$ & $\%$ \\
\hline $\begin{array}{l}1 \text { step } \\
\text { steps }\end{array}$ & 5 & 16.7 & 0 & 0 \\
3 steps & 12 & 40.0 & 10 & 33.3 \\
4 steps & 6 & 20.0 & 6 & 20.0 \\
5 steps & 5 & 16.7 & 6 & 20.0 \\
0 steps & 2 & 6.7 & 8 & 26.7 \\
\hline statistics & 0 & 0 & 0 & 0 \\
& & $\mathrm{M}=2.56$ & & $\mathrm{M}=3.40$ \\
t-test for Equality & $\mathrm{S} . \mathrm{D} .=1.16$ & & $\mathrm{~S} . \mathrm{D} .=1.22$ \\
of Means & $\mathrm{t}=-2.70$ & $\mathrm{df}=58$ & $\mathrm{p}=0.005$ \\
\hline $\begin{array}{l}\text { Levene's Test for Equality } \\
\text { Variances }\end{array}$ & of & $\mathrm{F}=0.665$ & $\mathrm{df}=58$ & $\mathrm{p}=0.418$ \\
\hline
\end{tabular}

Table 3 shows basic statistical parameters such as arithmetic mean, standard deviation and variance of results for each sub-sample of participants. Measurable space of experimental testing was limited by variables of cognitive space perception of lower extremities in monitoring the success rate of correctly following marked traces with eyes closed, while walking forward and backwards. In measurable space, the examination of cognitive space perception in following footsteps, moving in the direction of arithmetic mean area, showed a difference between children who are deaf or hard-of-hearing and children who are typically hearing (2.83-4.33), also shown by the standard deviation $(1.49-0.84)$. 
Arithmetic means for variable of backward movements on given footsteps for children who are deaf or hard-of-hearing amounts to 2.57, whereas the mean for children who are typically hearing is 3.40. Standard deviations and variances did not demonstrate a signifi- cant departure for sub-samples; however, minimal differences are present for the participants with respect to the arithmetic mean of the total values - participants who are deaf or hard-of-hearing (1.17) and participants who are typically hearing (1.22), (Table 3 ).

Table 3 Comparative analysis of basis statistical parameters between deaf and hearing children (Tests of Equality of Group Means)

\begin{tabular}{|c|c|c|c|c|c|c|c|}
\hline \multirow{3}{*}{ Variables } & \multicolumn{5}{|c|}{ Group } & \multirow[b]{3}{*}{$\mathrm{F}$} & \multirow[b]{3}{*}{$\mathrm{P}$} \\
\hline & \multirow[b]{2}{*}{ MV } & \multicolumn{2}{|l|}{ Deaf } & \multicolumn{2}{|c|}{ Hearing } & & \\
\hline & & SD & MV & $\mathrm{SD}$ & $\begin{array}{l}\text { Wilks' } \\
\text { Lambda }\end{array}$ & & \\
\hline $\begin{array}{l}\text { Walking forward on marked } \\
\text { traces }\end{array}$ & 2,83 & 1,49 & 4,33 & 0,84 & 0,71 & 23,08 & 0,00 \\
\hline $\begin{array}{l}\text { Walking backward on } \\
\text { marked traces }\end{array}$ & 2,57 & 1,17 & 3,40 & 1,22 & 0,88 & 7,32 & 0,05 \\
\hline
\end{tabular}

\section{DISCUSSION}

Results have shown statistical significance for the variable of "Walking forward on marked traces", at the level of $\mathrm{p}=0.00$ with $\mathrm{F}=23.08$. Fisher's differences test for the variable of "Walking backward on marked traces" is 7.32 and discriminates the variability of applied sub-samples at the statistical level of $\mathrm{p}=0.05$. Based on such results, it can be concluded that children who are deaf or hard-of-hearing displayed significantly worse results with respect to children who are typically hearing, confirming our research hypothesis, which predicted that a statistically significant difference exists between populations of children who are deaf or hard-of-hearing and children who are typically hearing in perception of marked shapes (walking forward and backwards on marked traces). These findings reveal that the experimental group (participants who are deaf or hard-of-hearing) displayed significantly poorer results on limited tests of cognitive space perception than the control group (participants who are typically hearing), shown most strongly for the variable of "Walking forward on marked traces". This research studied the cognitive space perception of children who are deaf or hardof-hearing through moves in space and manipulative field, for which research hypothesis was predicted. With respect to the level of importance, children who are typically hearing demonstrated better results in overall capabilities of cognitive space perception of personal body manifestations in relation to children who are deaf or hard-of-hearing. These results indicate that children who are typically hearing use their visual-spatial skills significantly better than children who are deaf or hard-of-hearing, which is in accordance with other research studies that reached conclusions on Visual Survey (Myklebust, 1950, per Peter, et.al, 2007).

According Wiegersma and Vander Velde (2003), comparisons between a group of children who are deaf or hard-of-hearing and controls who are typically hearing on an extensive test-battery revealed that the former group was clearly inferior both in general dynamic coordination and visual-motor coordination in an experimental study which focused on speed of motor performance. These findings confirmed the general impression that children who are deaf or hard-of-hearing are relatively slow performers. In particular, the execution of movements is slower in children who are deaf or hard-of-hearing; however, the processes involved in this difference require further experimental research.

Horn, Pisoni, Miyamoto (2006) concluded that atypical motor development in deaf children who are deaf or hard-of-hearing may not be generalized while Zwierzchowska, Gawlik, Grabara (2008) stress that it cannot be concluded that the lack of hearing determines motor development.

Peter et.al. (2007), Quittner et al. (Quittner, Smith, Osberger, Mitchell, Katz, 1994; Smith, Quittner, Osberger, Miyamoto, 1998) have recently observed that children who are deaf or hard-of-hearing performed worse than hearing controls when asked to detect a pre-specified sequence of digits among a stream of visually presented digits, suggesting difficulties in visual selection. These results have led some to propose that deafness results in deficits in space perception cognition (Quittner, Leibach, Marciel, 2004). 
Assessment of the longitudinal arch of the foot in children who are deaf or hard-of-hearing and children who are typically hearing aged 9 to 11 years is established that no statistically significant differences were found between the studied groups in terms of the index of the foot arch in loading and unloading (Kamińska, Wiernicka, Górny, 2009).

Savelsbergh, Netelenbos, 1992 showed that children who are deaf or hard-of-hearing do have a problem in localizing targets outside their initial field of view. The consistent outcome of significantly slower eye and head latency times, movement times, and localization times for the persons who are deaf in respect to targets initially outside the field of view suggest that on the representational level, localization seems to be affected. Melo, et all (2012) established that children with sensorineural hearing loss can suffer neuromotor developmental delays and problems with certain motor abilities, may complain of discomfort during games that are typical of their age and, most importantly, may have difficulties keeping up with other children of the same age and sex and interacting with their peers.

Results of this study show that populations that are deaf or hard-of-hearing, when it comes to the visual memory of body position in micro space, are greatly disadvantaged in comparison to the populations that are typically hearing. Most likely, it is a matter of reliance of persons who are deaf or hard-of-hearing on their sense of sight. By excluding this sensual modality, persons who are deaf or hard-of-hearing may have significant problems in new and unpredictable situations, when the influence of visual senses is reduced. The findings point out to the great need for programming of rehabilitation treatment, which should include exercises and practice on personal body perception of persons who are deaf or hard-of-hearing in reduced states of visual sensors. This research reveals significant problems of persons who are deaf or hardof-hearing, which confront cognition and retention of movable elements of their own body with its interaction in futuristic and unpredictable situations as it is the stumbling at dark places.

Results suggest the need for further research that will focus on uncovering these and other problems of persons who are deaf or hard-of-hearing. The projection for the variable of perception of body signs indicates the fact that persons who are deaf or hard-of-hearing, in relation to persons who are typically hearing, is are generally disadvantaged in the area of cognitive perception of body manifestations in situations when their eyes are closed.

\section{Conclusion}

On the basis of achieved results of the research, it can be concluded that children who are deaf or hard-ofhearing have shown significantly weaker perception of body movements in comparison to children children who are typically hearing.

\section{Limitations}

Participants younger than 6 years old were not included in the study because of the established criteria of cognitive development which states that during the first 6 years of life, the difficulties in development of spatial cognition cannot be considered due to the fact that both hearing and deaf children show maximum level of motor development and sense of awareness through the use of movements and motion. It is considered those children who are hearing impaired as other children have certain difficulties because of lack of experience while moving at different unknown areas, in early sensor-motor development. Because of different individual experiences and specific school activities of physical Education children above age of 6 are taken for the sample. The main goal of this activity was to research mobile elements of awareness functions within a manipulated field and space, in which deaf children develop interactions with objective reality and learned materials. Interactions with the world are made daily by game, sport but also by obstacles that are related to movement. In analysing results, descriptive analysis was looked at first, which included double-checking the normal distribution. In analysing frequencies and percentages, a comparative analysis of the results between the sub samples was applied at the frequency level, while comparative descriptive analysis was done for the main statistical parameters in measured space. The study made sure that during the operating parts of the research, gender equality was equally represented by participants in both controlled and experimental groups. The reason for monitoring results for males and females separately is to determine whether or not gender plays a role in influencing or somehow differently affecting cognitive space perception. It was found that there was no significant difference between the sexes. Although the results of the current study indicate negative outcomes, several limitations must be noted. First, children who are deaf didn't were of the same chronological age. Second, different individual abilities in children should be taken into consideration. 


\section{Implications for Research}

As one of the first studies measuring the effects of on body coordination, without use of eyesight of students who are deaf, the current study raises important questions for future research. One question to consider is the extent to which the students mastered the concepts versus memorizing a movement in situations when children who are deaf cannot rely on eyesight. Another focus for future research is the extent to which students are able to generalize the body in space to real life activities. Although general education children who are deaf often the not assumes this generalization, students who hard deaf may need opportunities to apply their skills to daily living.

\section{Declaration of Conflicting Interests}

The author declared no potential conflicts of interest with respect to the authorship and/or publication of this article.

\section{Funding}

The author received no financial support for the research and/or authorship of this article.

\section{Note}

A table describing all standards and the specific responses measured is available from the author

\section{Acknowledgements}

I want to thank Dr. Kevin Miller for editing and suggestions, who is professor on Concordia University, Department of Special Education, Nebraska.

\section{REFERENCES}

Corina, D., Singleton, J. (2009). Developmental Social Cognitive Neuroscience: Insights from Deafness. Child Development, 80, 952-967. [Online]. Available from: http:// www.ncbi.nlm.nih.gov/pubmed/19630887

Gheysen, F, Loots, G, Waelvelde, H. (2008) Motor Development of Deaf Children with and Without Cochlear Implants. Journal of Deaf Studies and Deaf Education 13:2. doi:10.1093/deafer/ enm053. [Online]. Available from:

http://jdsde.oxfordjournals.org/content/13/2/215.full.pdf + html

Horn, D.L., Pisoni, D.B., Miyamoto, RT. (2006). Divergence of fine and gross motor skills in prelingually deaf children: Implications for cochlear implantation. Laryngo-scope, 116, 15001506. [Online]. Available from:

http://www.ncbi.nlm.nih.gov/pmc/articles/PMC3314263/
Imai, T., Moore, S.T, Raphan, T., Cohen, B. (2001) Interaction of the body, head, and eyes during walking and turning. Exp Brain Res (2001) 136:1-18. DOI 10.1007/s002210000533. [Online]. Available from: http://www.ncbi.nlm.nih.gov/pub$\mathrm{med} / 11204402$

Kamińska, E., Wiernicka, M., Górny, M. (2009.) The assessment of the longitudinal arch of the foot in deaf and hearing children aged 9 to 11 years. Acta Univ. Palacki. Olomuc., Gymn. 2009, vol. 39, No. 1. [Online]. Available from:

http://www.gymnica.upol.cz/index.php/gymnica/article/viewFile/186/126

Marschark, M. (2003). Cognitive Functioning in Deaf Adults and Children. In Marchark, M \& P.E. Spencer, Deaf Studies, Language and Education (pp. 464-478). New York: Oxford. doi: 10.1093/oxfordhb/9780195390032.001.0001

Melo, R.S., Silva, P.W.A., Tassitano R.M, Macky, C.F. S.T., Silva, L.V.C. Balance and gait evaluation: comparative study between deaf and hearing students. Rev Paul Pediatr 2012; 30(3): 385-91. [Online]. Available from: http://www.scielo.br/pdf/rpp/ v30n3/en_12.pdf

Peter, H.C., Cohen, J., Dye, M.W.G., Bavelier, D. (2007). Visual Constructive and Visual-Motor Skills in Deaf Native Signers. J. Deaf Stud. Deaf Educ, 12 (2):148-157. doi:10.1093/deafed/ enl030.

Quittner, A. L., Smith, L. B., Osberger, M. J., Mitchell, T. V., Katz, D. B. (1994). The impact of audition on the development of visual attention. Psychological Science, 5, 347-353. doi: 10.1111/j.1467-9280.1994.tb00284.x

Quittner, A. L., Leibach, P., Marciel, K. (2004). The impact of cochlear implants on young deaf children: New methods to assess cognitive and behavioral development. Archives of Otolaryngology and Head Neck Surgery, 130, 547-554. doi:10.1001/ archotol.130.5.547.

Rettenback, R., Diller, G., Sireteneau, R. (1999). Do deaf people see better? Texture segmentation and visual search compensate in adult but not in juvenile subjects. Journal of Cognitive Neuroscience, 11, 560-583. doi: 10.1162/089892999563616

Savelsbergh, Geert J.P., Netelenbos, J. B. (1992) Can the Developmental Lag in Motor Abilities of Deaf Children be Partly Attributed to Localization Problem? Adapted Physical Activity Quarterly, Vol 9(4), Oct 1992, 343-352. [Online]. Available from: http://psycnet.apa.org/psycinfo/1993-10436-001

Smith, L. B., Quittner, A. L., Osberger, M. J., Miyamoto, R. (1998). Audition and visual attention: The developmental trajectory in deaf and hearing populations. Developmental Psychology, 34, 840-850. doi: 10.1037/0012-1649.34.5.840

Wiegersma P. H., Vander Velde, A. (2006). Motor development of deaf children, Journal of Child Psychology and Psychiatry, 24, I (1), 103-111.

Zwierzchowska, A., Gawlik, K., Grabara, M. (2008). Deafness and motor abilities level. Biology of Sport, 25 (3), 263-274. [Online]. Available from: http://www.doaj.org/ doaj?func $=$ fulltext\&aId $=634810$ 